\title{
Measuring the Systematic Risk of Stocks Using the Capital Asset Pricing Model
}

\author{
Abonongo John", Ackora-Prah J., Kwasi Boateng \\ Department of Mathematics, College of Science, Kwame Nkrumah University of Science and Technology, Kumasi, Ghana \\ Email address: \\ abonongojohn@gmail.con (A. John) \\ ${ }^{*}$ Corresponding author \\ To cite this article: \\ Abonongo John, Ackora-Prah J., Kwasi Boateng. Measuring the Systematic Risk of Stocks Using the Capital Asset Pricing Model. Journal \\ of Investment and Management. Vol. 6, No. 1, 2017, pp. 13-21. doi: 10.11648/j.jim.20170601.13
}

Received: September 13, 2016; Accepted: September 30, 2016; Published: December 14, 2016

\begin{abstract}
Among the paramount information in the stock market is the awareness of the systematic risk of stocks which plays essential role in investment choices. This paper measured the systematic risk of seven stocks on the Ghana Stock Exchange (GSE) using monthly closing prices and the 91 day T-bill from the period 2011 to 2015. The CAPM was employed in measuring the systematic risk of the stocks. The results revealed that, CAL, FML and TLW were defensive stocks since each had a market beta less than one (1). PBC, CLYD, EGL and UNIL had the same systematic risk as the market since each recorded a market beta of one (1). All the seven stocks each had a positive market beta implying that they move in a similar manner as the market. The compensation for investing in each of the stock was approximately at $3 \%$. The diversifiable risk associated with each of the stock was very low since few of the returns were scattered along the regression line.
\end{abstract}

Keywords: Systematic Risk, CAPM, Risk Premium, Market Beta, Expected Return

\section{Introduction}

Systematic risk is the component of risk that comes as a result of factors that affects the entire market. Thus, it refers to the variation of return on stocks associated with changes in the return on the market in general.

Modern portfolio theory formed the foundation of the Sharpe-Lintner Capital Asset Pricing Model (CAPM). The main idea of the CAPM is that the rate of return on an asset will be equal to the risk free rate plus a risk premium. It is used to estimate theoretically the required rate of return given a level of risk which is usually called beta coefficient. The CAPM and the concept of beta as a measure of systematic risk have numerous practical applications in portfolio management. It gives a rationale for passive portfolio strategy. Diversifying your risky assets according to the proportions of market portfolio and mix this portfolio with the risk-free asset to achieve a desired risk-reward combination [10]. The total risk of investing in a stock comprises of two risk. The CAPM explains one of them as the risk associated with the market. [6] identified this type of risk as the systematic risk. This kind of risk is undiversifiable (unavoidable). The other type, is the unsystematic risk; the risk specific (unique) to a company or stock. Sharpe figured out that a portfolio's expected return hinges solely on its beta and its relationship with the overall market. The CAPM assist in measuring portfolio risk and the expected return associated with it.

[9] estimated the systematic risk for 17 listed industrial companies and examined the relationship between these values and the debt to equity ratios of the companies from 1992 to 1996 . They concluded that the debt to equity ratio was not a significant determinant factor of beta.

[3] found a positive relation between return and risk. The data used for the study was monthly percentage returns for all equities traded on the New York Stock Exchange (NYSE) from January 1926 to June 1968. An extended model of returns was used to arrive at their conclusion. Using two to five years of prior monthly returns, they estimated the beta for every equity on the NYSE, the American Stock Exchange (1963-2003) and the NASDAQ (1972-2003). Ten portfolio were derived from these estimated betas and their returns for the next 1 month was computed. The process was repeated for each year from 1928 to 2003 . The results confirmed that the relation between beta and average return for the ten 
portfolios was much flatter than predicted by the CAPM, as the return on low beta portfolios were too high and the return on high beta portfolios were too low.

[1] investigated the relationship between stock returns and systematic risk based on CAPM in the Bombay Stock Exchange (BSE). The sample search was 287 top companies of BSE from January 1996 to December 2009. Their findings (about intercept and slope of CAPM equation that stocks intercept should equal from zero and slope should be excess returns) rely on negate hypothesis of CAPM and offers evident against the CAPM. Also, their results revealed that residual risk has no effect on the expected return of portfolios. [12] tested the CAPM to see if higher return has been associated with higher risk over a longer periods of time. For each year from 1931 to 1967 , beta was measured using 60 months of previous data and all equities on the NYSE were divided into deciles based on their betas. Their results showed that there was a positive relation between return and beta and that the relationship was both strong and linear [2].

[7] examined equilibrium model for the inter-temporal evolution of the basis in foreign currency markets. The weights were specified in a hedged by the prices of futures and spot contracts position and by internal and external interest rates. Eventually this hedged position using an intertemporal asset pricing model led to a testable equilibrium model of the future basis. Their results showed that, the estimated inter-temporal risk was insignificantly differently from zero, the risk in the futures market offset that in the spot providing an effective hedge. [8] examined the relationship between stock returns and systematic risk based on CAPM in Tehran Stock Exchange from the period 1387 to 1392 . The results showed that the relationship between systematic risk and stock returns was statistically significant. Also, the nonlinear (quadratic) function outperformed the linear one explaining the relationship between systematic risk and stock returns and that the CAPM in the sample was rejected and does not exist linear relationship between systematic risk and stock returns in the sample.

[4] examined the economic determinants of systematic risk in the Jordanian Capital Market using the Ammam Stock Exchange as a representation of emerging Arab financial markets. The results revealed that, several factors including size, financial leverage, government deficit and inflation rate significantly affect a company's systematic risk value.

The purpose of this paper is to measure the systematic risk of stocks using the CAPM. This is to provide investors with first-hand information on the sensitivity of stocks to movement (fluctuation) in the market so as to make the right investment choices.

\section{Materials and Methods of Analysis}

\subsection{Source of Data}

This paper employed secondary data of 7 stocks from the Ghana Stock Exchange (GSE) and the Annual Report Ghana databases comprising monthly closing prices and the 91 day T-bill from the period 2011 to 2015.

\subsection{Methods of Data Analysis}

The Capital Asset Pricing Model (CAPM) of Sharpe [11] and Lintner [5] marked the beginning of asset pricing theory. When there is a risk-free rate, expected return on assets that are uncorrelated with the market return then, the $E\left(R_{m}\right)$ must be the same as the risk-free rate, $R_{f}$.

The CAPM assumes that;

i. when buying and selling securities there are no transactions and taxes cost involve

ii. when evaluating investments, the capital market are in equilibrium and all investments are properly priced in line with the level of risk. Hence, no arbitrage opportunities for investors.

iii. all investors have homogeneous expectations of returns

iv. the existence of a risk-free rate, meaning investors have access to the risk-free rate (no limit to the amount that may be borrowed or lend at the risk-free rate)

v. the returns follows a normal distribution

vi. it is a one period model.

Therefore, the link between the expected return $E\left(R_{i}\right)$ and market beta $\left(\beta_{i m}\right)$ is given by Sharpe-Lintner CAPM formula;

$$
E\left(R_{i}\right)=R_{f}+\beta_{i m}\left[E\left(R_{m}\right)-R_{f}\right] ; i=1, \ldots N
$$

where $E\left(R_{i}\right)$ is the expected return on stock $i, R_{f}$ is the riskfree rate, $E\left(R_{m}\right)$ is the expected return on the market and $\beta_{i m}$ is the market beta of stock $i$. The size of the compensation depends on the equilibrium risk premium, $E\left(R_{m}\right)-R_{f}$.

The market beta of stock $i$ is given by;

$$
\beta_{i m}=\frac{\operatorname{Cov}(i, m)}{\sigma_{m}^{2}}=\frac{\operatorname{Cov}\left(R_{i}, R_{m}\right)}{\sigma_{R m}^{2}}
$$

where $\operatorname{Cov}\left(R_{i}, R_{m}\right)$ is the covariance of the return of stock $i$ and the market return and $\sigma_{R m}^{2}$ is the variance of the market return. If $\beta_{\text {im }}>1$, it implies that the stock is an aggressive type (has more undiversifiable risk than that of the market). If $\beta_{i m}<1$, it means that, the stock is a defensive type (implies that excess return for the stock is inversely related to the excess return of the overall market). Also, if $\beta_{i m}=1$, implies the stock has the same systematic risk as the market.

The risk premium on stock

$$
\mathrm{i}=\frac{R_{m-R_{f}}}{\sigma_{m}^{2}} \times \operatorname{Cov}(i, m)=\left(R_{m-R_{f}}\right) \beta_{i m}
$$

Jenson recognised that the Sharpe-Lintner CAPM implies a time series regression test. He said that the Jensen's Alpha is zero for each asset. From the CAPM formula in Equation (1), we deduce that,

$$
E\left(R_{i}\right)-R_{f}=\beta_{i m}\left[E\left(R_{m}\right)-R_{f}\right]
$$

The excess return on stock $i$ is given by;

$$
R_{i}^{e}(t)=R_{i}(t)-R_{f}
$$


The excess return on the market is given by;

$$
R_{m}^{e}(t)=R_{m}(t)-R_{f}
$$

Putting Equation (4) and (5) into Equation (3), the time series regression test is given by;

$$
R_{i}^{e}(t)=\alpha_{i}+\beta_{i m}+R_{m}^{e}(t)+\varepsilon_{i}(t)
$$

where $\alpha_{i}$ is the risk-adjusted measure of the return on stock $i$, $\varepsilon_{i}(t)$ reflects the idiosyncratic (diversifiable) risk of stock $i, \alpha_{i}$ $=0, E\left(\varepsilon_{i}(t)\right)=0$ and $\operatorname{Cov}\left(\varepsilon_{i}(t), R_{m}\right)=0$. When $\alpha_{i}<R_{f}$ then, either the stock has earned very little for its risk or is very risky for the return. When $\alpha_{i}>R_{f}$ then, the stock earned a return in excess of the risk assumed and when $\alpha_{i}=R_{f}$ then, the stock earned a return appropriate to the risk assumed. In an efficient market, $E\left(\alpha_{i}\right)=R_{f}$

\section{Results and Discussion}

\subsection{Descriptive Statistics}

Table 1 shows the summary statistics of the stocks. It is evident that, CAL, FML, EGL and UNIL had positive mean returns of $0.032,0.009,0.154$ and 0.041 respectively, an indication of gains whereas PBC, CLYD and TLW recorded negative mean returns of $0.013,-0.045$ and -0.095 respectively, an indication of losses. The highest mean return was recorded in EGL (0.154) whereas the lowest mean return was recorded in TLW (-0.095). The highest standard deviation was in TLW (0.926) and the lowest standard deviation was in UNIL (0.270) an indication of the level of risk associated with the stocks. The coefficient of variation (CV \%) ranges from 5.873 (EGL) to 39.572 (FML) as a measure of the variability in the returns. Also, the returns of CAL, FML, CLYD, and TLW were negatively skewed, indicating that there was high probability of investors of these stocks making losses than gains. In that same vain, the returns of PBC, EGL and UINL were positively skewed implying investors had greater probability of making gains than losses. All the stocks with the exception of PBC had excess kurtosis less than 3 an indication of that the returns were leptokurtic and less peaked from the normal distribution.

\begin{tabular}{|c|c|c|c|c|c|}
\hline Stock & Mean & Std. Dev & $\mathrm{CV}$ & Skewness & Excess Kurtosis \\
\hline CAL & 0.032 & 0.422 & 13.009 & -2.672 & 16.114 \\
\hline PBC & -0.013 & 0.313 & 23.467 & 0.195 & 2.459 \\
\hline FML & 0.009 & 0.345 & 39.572 & -0.427 & 3.673 \\
\hline CLYD & -0.045 & 0.324 & 7.209 & -0.529 & 7.260 \\
\hline EGL & 0.154 & 0.906 & 5.873 & 0.045 & 4.672 \\
\hline UNIL & 0.041 & 0.270 & 6.636 & 3.496 & 20.264 \\
\hline TLW Other Variables & -0.095 & 0.926 & 9.699 & -3.377 & 19.647 \\
\hline$R_{m}$ & 0.061 & 1.112 & 3.197 & 0.598 & 3.814 \\
\hline
\end{tabular}

Table 1. Descriptive Statistics of the Returns Series.

The time series plots in Figure (1), (2), (3), (4), (5), (6), (7), (8) and (9) of the monthly returns of CAL, PBC, FML, CLYD, EGL, UNIL, TLW, Risk-free rate and the Market shows that, the returns have some trends in them and that most of them have been increasing over time with the exception of the UNIL and the Risk-free rate.

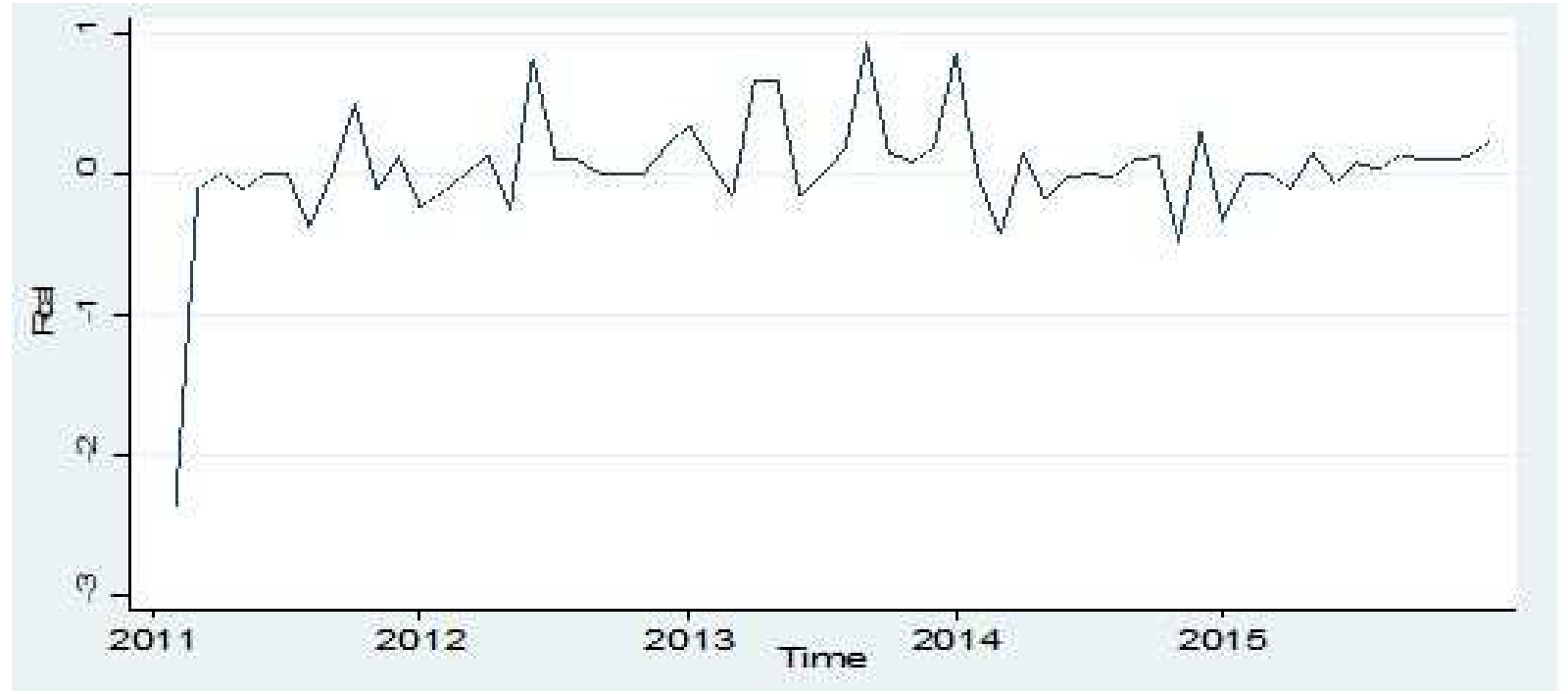

Figure 1. Time Series Plot of CAL Monthly Returns. 


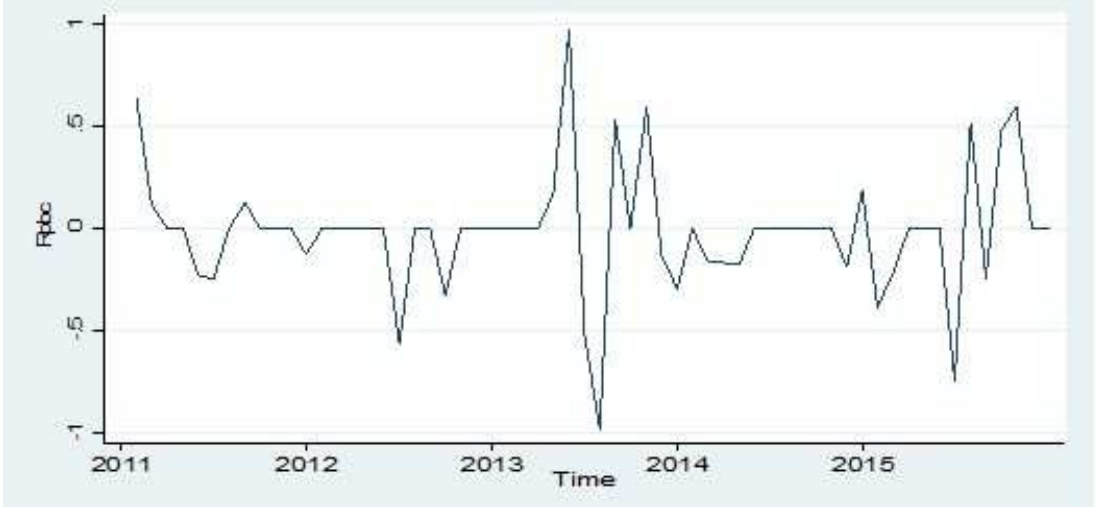

Figure 2. Time Series Plot of PBC Monthly Returns.

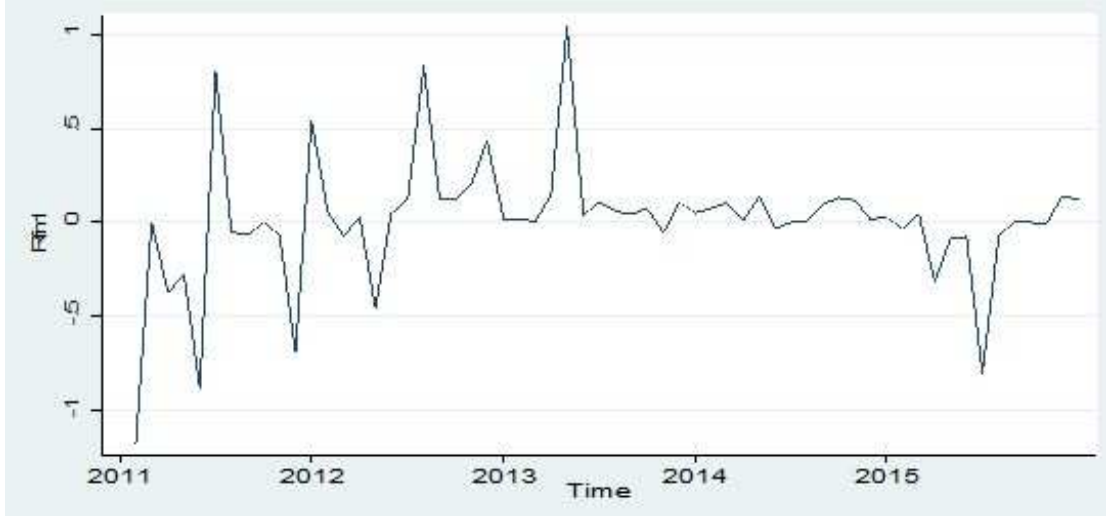

Figure 3. Time Series Plot of FML Monthly Returns.

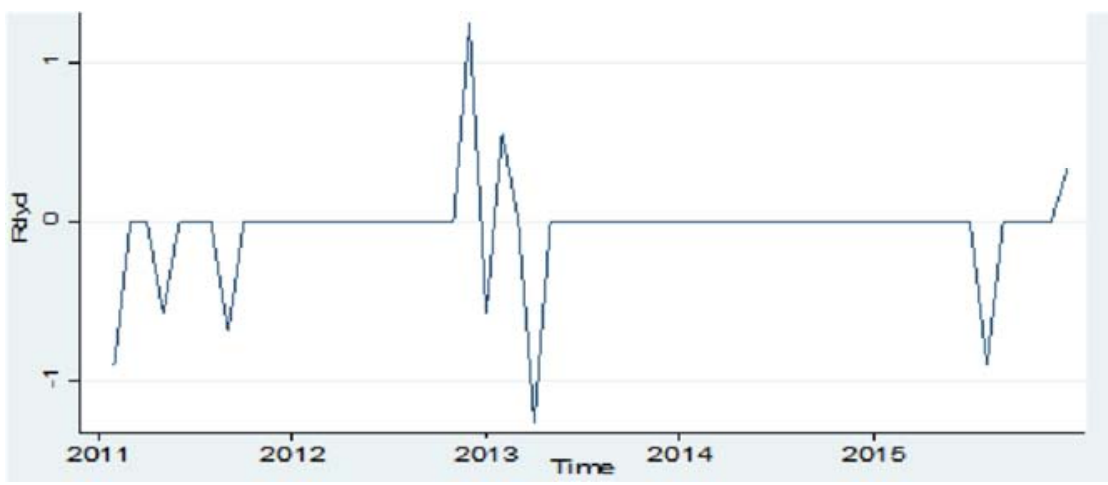

Figure 4. Time Series Plot of CLYD Monthly Returns.

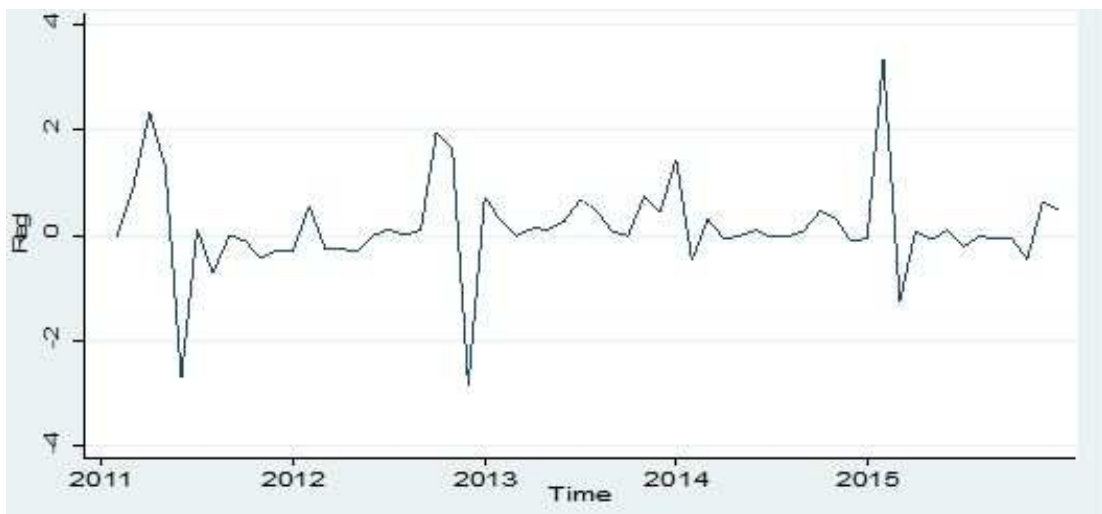

Figure 5. Time Series Plot of EGL Monthly Returns. 


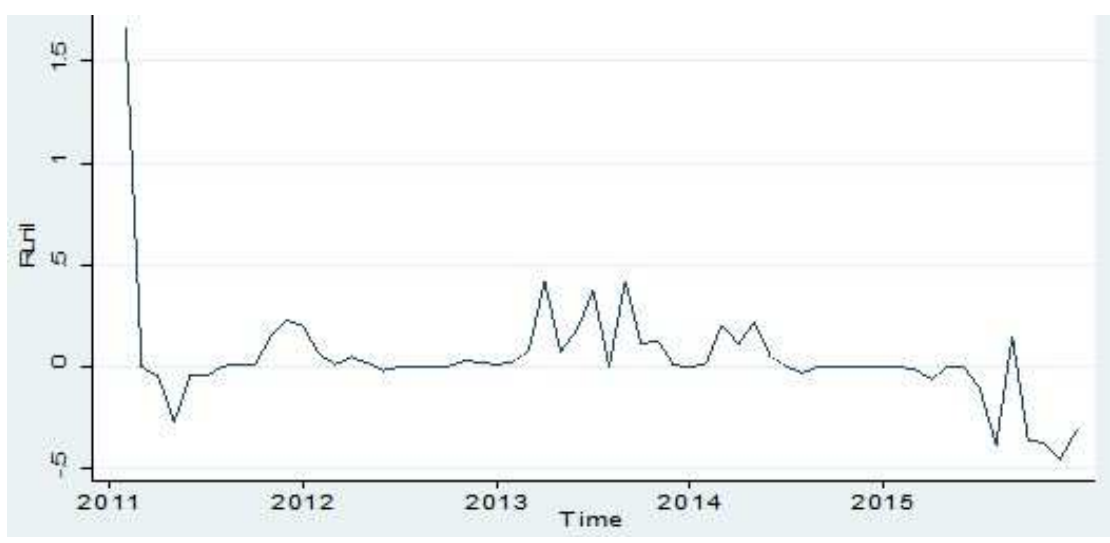

Figure 6. Time Series Plot of UNIL Monthly Returns.

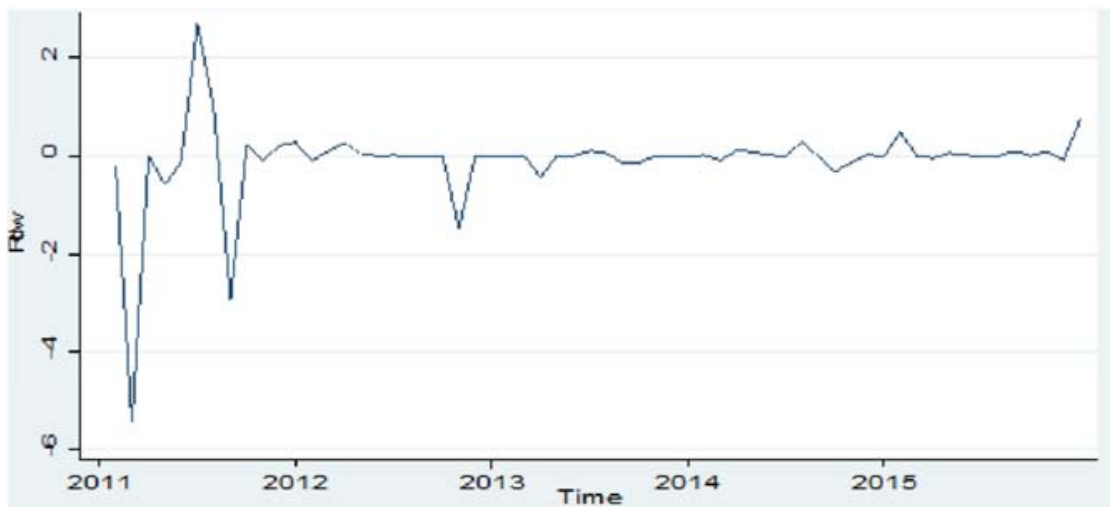

Figure 7. Time Series Plot of TLW Monthly Returns.

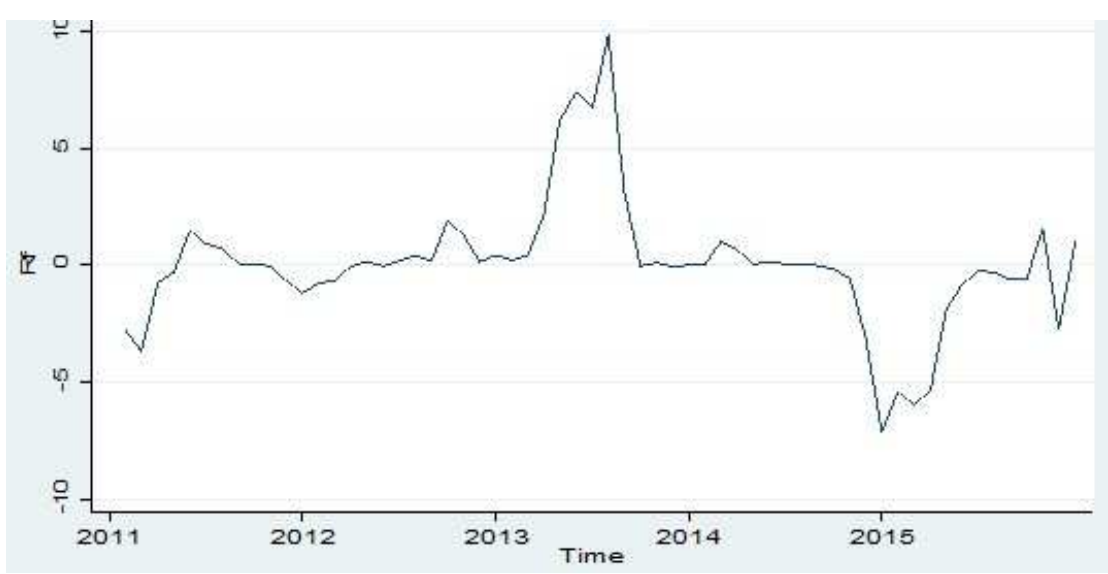

Figure 8. Time Series Plot of the Returns on the Risk-free rate.

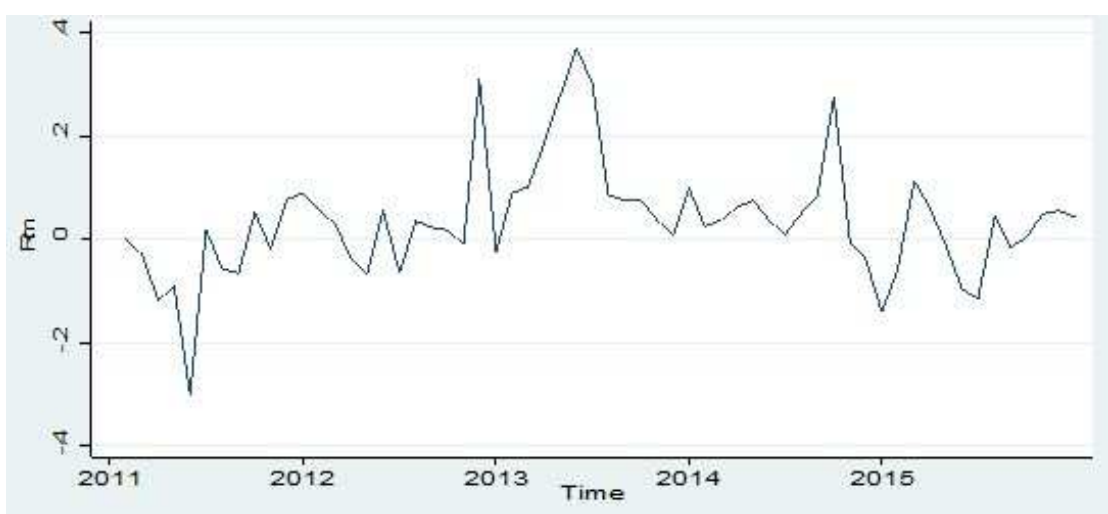

Figure 9. Time Series Plot of Monthly Market Returns. 


\subsection{Further Analysis}

Table 2 shows the CAPM estimates of the 7 stocks. It is evident that, CAL, FML, and TLW had their market betas been less than (1) an indication that they are defensive stocks and that their excess return varies proportionally with that of the market. This also shows that, CAL, FML and TLW have their returns moving in the same direction as the market, but in a lesser extent (approximately $0.978 \times, 0.988 \times$ and $0.972 \times$ respectively). Also, PBC, CLYD, EGL and UNIL have their market betas equal to one (1) indicating that they have the same systematic risk as the market. This also indicates that, the returns of PBC, CLYD, EGL and UNIL will move in the same direction as the market in response to systematic risk by

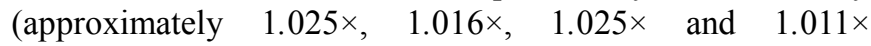
respectively). Again, since all the stocks recorded positive market betas it imply that, the prices of these stocks have the tendency of increasing when the market rises and vice versa. Therefore, it is evident from Table 3 that, when the market moves up by $6.1 \%$, share price in CAL, PBC, FML, CLYD, EGL, UNIL and TLW will move up by $5.966 \%, 6.2538 \%$, $6.027 \%, 6.198 \%, 6.253 \%, 6.167 \%$ and $5.929 \%$ respectively whereas a $6.1 \%$ fall in the market returns will cause share price in CAL, PBC, FML, CLYD, EGL, UNIL and TLW to fall by $5.966 \%, 6.2538 \%, 6.027 \%, 6.198 \%, 6.253 \%, 6.167 \%$ and $5.929 \%$ respectively. In the same vein, when the market returns move up by $10 \%$, share price of CAL, PBC, FML, CLYD, EGL, UNIL and TLW will move up by $9.780 \%$, $10.250 \%, 9.880 \%, 10.160 \%, 10.250 \%, 10.110 \%$ and $9.720 \%$ respectively whereas a $10 \%$ fall in the market returns will cause the share price of CAL, PBC, FML, CLYD, EGL,
UNIL and TLW to fall by $9.780 \%, 10.250 \%, 9.880 \%$, $10.160 \%, 10.250 \%, 10.110 \%$ and $9.720 \%$ respectively. The risk-adjusted measure $\left(\alpha_{i}\right)$ for CAL, PBC, FML, CLYD, UNIL and TLW were all less than the risk-free rate $(0.035)$ indicating that the stocks were risky and either made little gains for the risk assumed whereas the risk-adjusted measure of EGL was greater than the risk-free rate indicating that, EGL earned returns in excess of the risk-premium.

Moreover, defensive stocks are not so much sensitive to movements in the market compared with aggressive stocks which amplifies any movement in the market. Therefore, investors are advice to stay with aggressive stocks when the market returns rise. Investors need to shift to defensive stocks any time the market falls and in this case, investors can consider investing in CAL, FML and TLW and stocks that have market betas of one (1) since a fall in the market will cause these stocks to fall at the same rate and vice versa. Thus, risk averse and risk neutral investors may consider investing in PBC, CLYD, EGL and UNIL since they have the same systematic risk as the market. Better still, they can consider investing in the defensive stocks since they do not reflect much movement on the market and as such when the market moves up/down these stocks are not affected much.

Table 4, shows the level of compensation for investing in each stock. It is evident that, all the seven stocks each has a compensation of approximately $3 \%$. This indicates that, investors of these stocks will be compensated at $3 \%$ in excess of the risk-free returns. Thus, investors will have their expected returns increased by 3\% more than the risk-free return as a compensation for the risk assumed.

Table 2. CAPM Estimates of the Seven Stocks.

\begin{tabular}{lllllll}
\hline Stock & $\boldsymbol{\alpha}_{\boldsymbol{i}}$ & $\boldsymbol{\beta i m}$ & Std. Error & t-ratio & P-value & Adjusted R \\
\hline CAL & -0.003 & 0.978 & 0.020 & 49.649 & $0.000^{* * *}$ & 0.977 \\
PBC & -0.048 & 1.025 & 0.015 & 70.054 & $0.000^{* * *}$ & 0.988 \\
FML & -0.026 & 0.988 & 0.015 & 66.718 & $0.000^{* * *}$ & 0.987 \\
CLYD & -0.079 & 1.016 & 0.015 & 65.985 & $0.000^{* * *}$ & 0.987 \\
EGL & 0.120 & 1.025 & 0.044 & 23.232 & $0.000^{* * *}$ & 0.901 \\
UNIL & 0.006 & 1.011 & 0.013 & 76.580 & $0.000^{* * *}$ & 0.990 \\
TLW & -0.131 & 0.972 & 0.044 & 21.961 & $0.000^{* * *}$ & 0.891 \\
\hline
\end{tabular}

***Significant at $5 \%$ significance level

Table 3. Movement of the stocks in Relation to Market Returns.

\begin{tabular}{llll}
\hline Stock & Bim & & Market Return \\
\hline & & $6.1 \%$ up/down & $10 \%$ up/down \\
CAL & 0.978 & 5.966 & 9.780 \\
PBC & 1.025 & 6.253 & 10.250 \\
FML & 0.988 & 6.027 & 9.880 \\
CLYD & 1.016 & 6.198 & 10.160 \\
EGL & 1.025 & 6.253 & 10.250 \\
UNIL & 1.011 & 6.167 & 10.110 \\
TLW & 0.972 & 5.929 & 9.720 \\
\hline
\end{tabular}


Table 4. Stocks and the required risk premium.

\begin{tabular}{ll}
\hline Stock & Risk Premium (\%) \\
\hline CAL & 2.546 \\
PBC & 2.665 \\
FML & 2.569 \\
CLYD & 2.642 \\
EGL & 2.665 \\
UINL & 2.629 \\
TLW & 2.527 \\
\hline
\end{tabular}

From Figure (10), (11),(12),(13), (14), (15) and (16), it is evident that, the excess return of CAL, PBC, FML, CLYD, EGL, UNIL and TLW moves with the excess market return almost at the same rate since most of the points (returns) were found precisely on the regression line. The few returns that were found scattered along the regression line indicates that, all the seven stocks have very little unique risk in relation to the market.

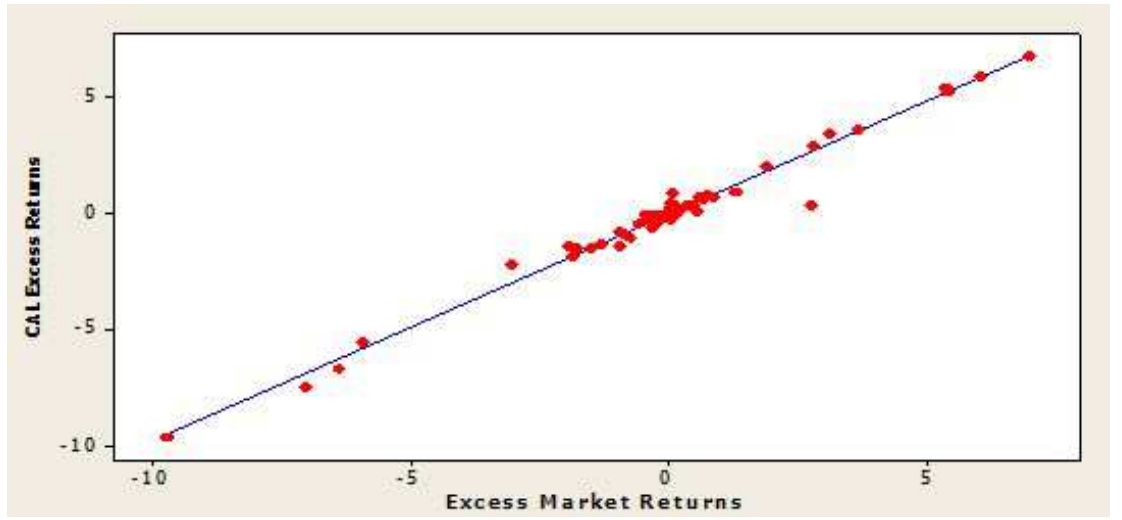

Figure 10. Excess CAL Returns vs Excess Market Returns.

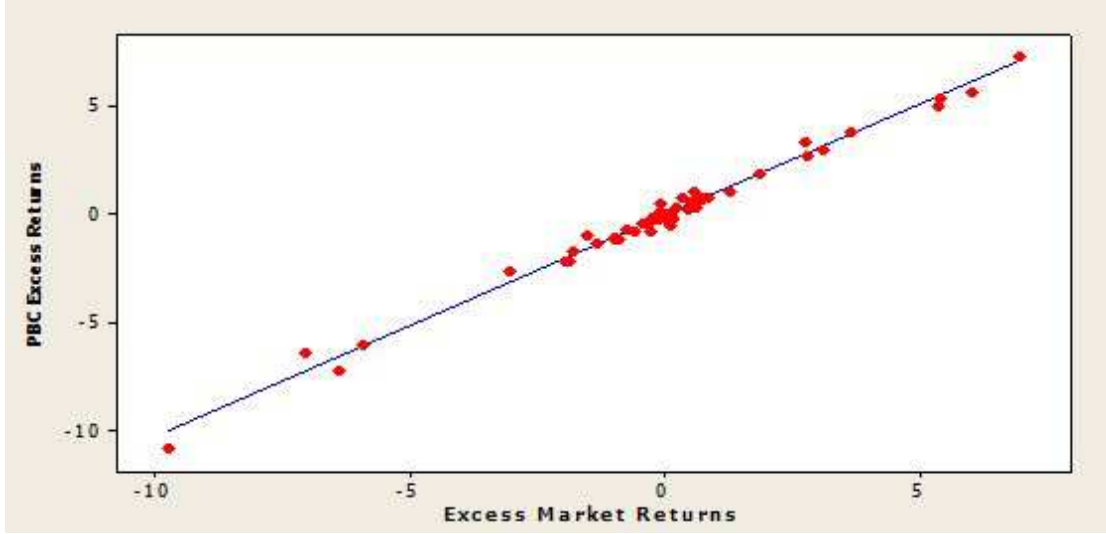

Figure 11. Excess PBC Returns vs Excess Market Returns.

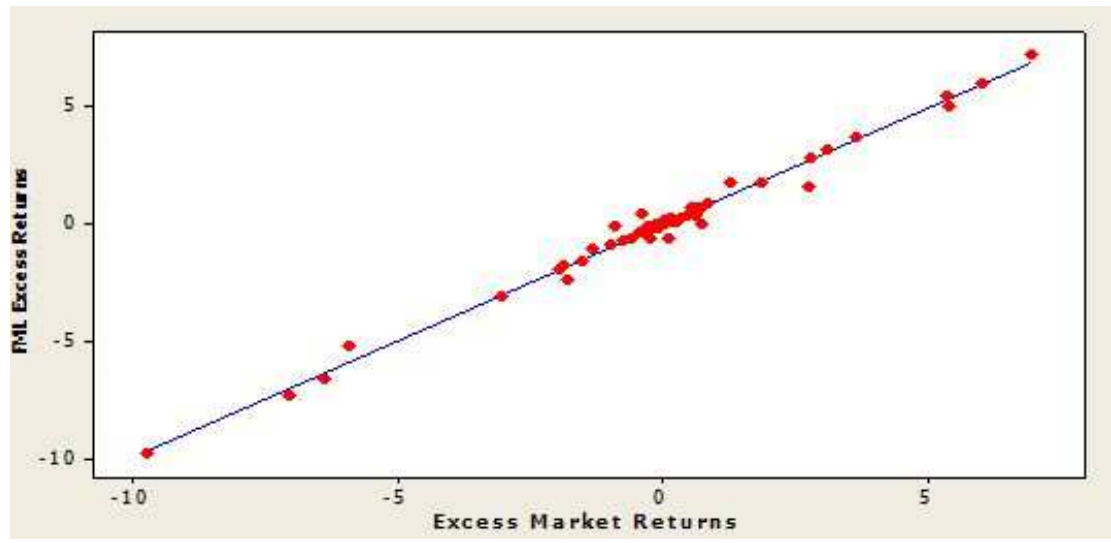

Figure 12. Excess FML Returns vs Excess Market Returns. 


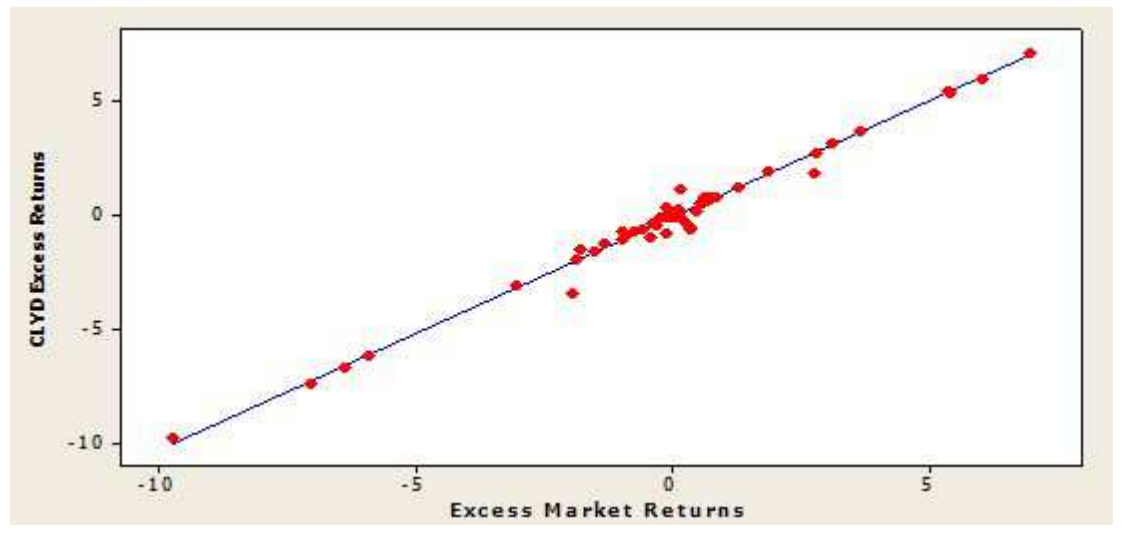

Figure 13. Excess CLYD Returns vs Excess Market Returns.

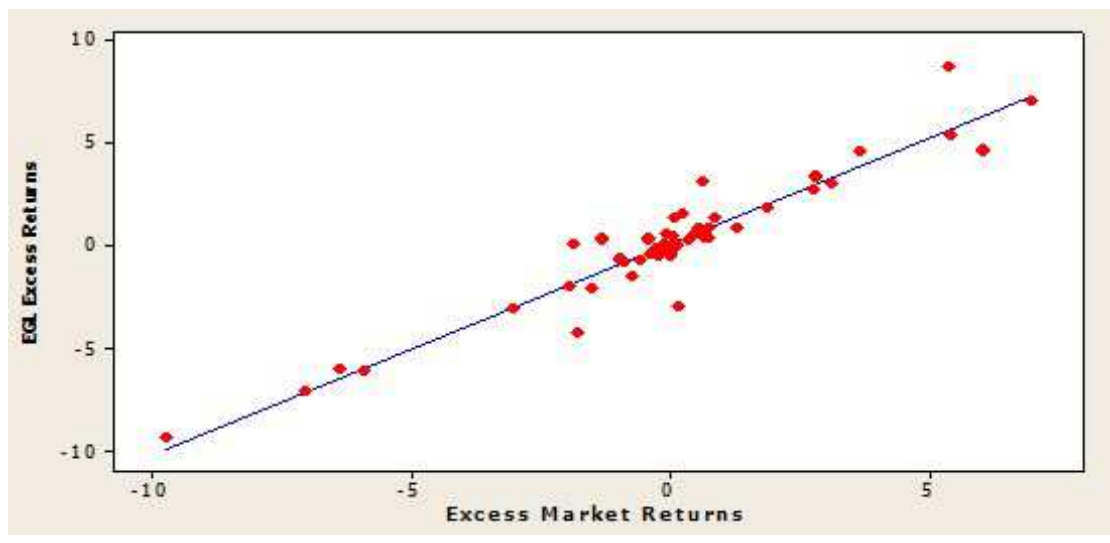

Figure 14. Excess EGL Returns vs Excess Market Returns.

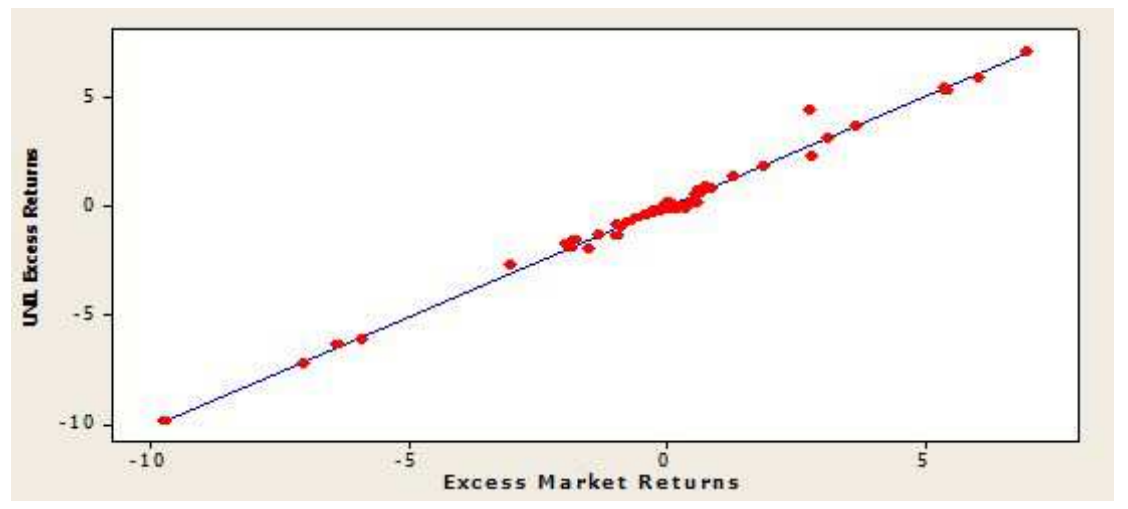

Figure 15. Excess UNIL Returns vs Excess Market Returns.

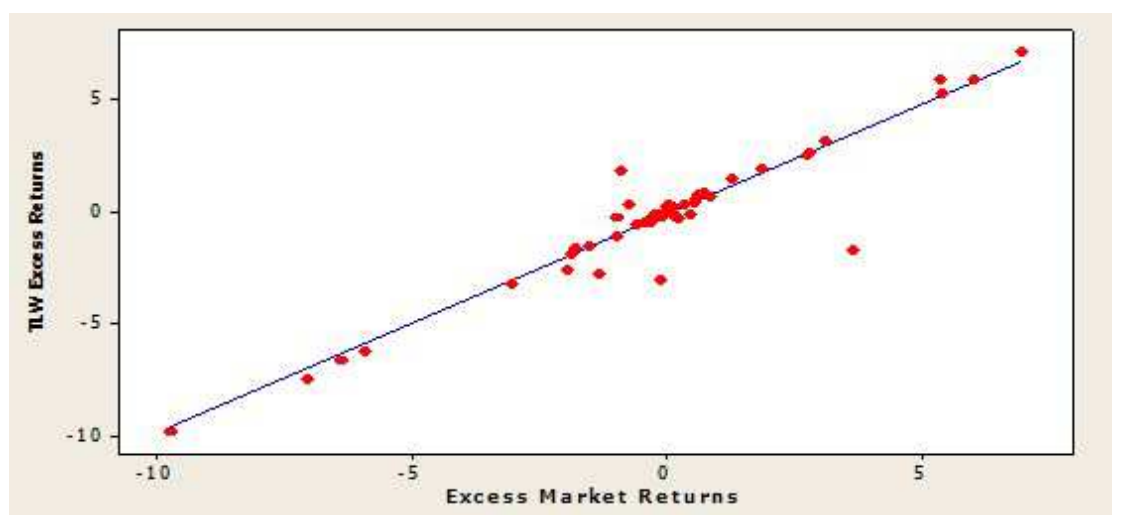

Figure 16. Excess TLW Returns vs Excess Market Returns. 


\section{Conclusion}

This paper measured the systematic risk of seven stocks on the Ghana Stock Exchange using the CAPM. The results revealed that, four of the stocks (PBC, CLYD, EGL and UNIL) had the same systematic risk as the market since they recorded market betas of one (1) each. The other three stocks (CAL, FML and TLW) had their market betas been less than one (1) making them defensive stocks. All the seven stocks recorded positive market betas which show that they have the same movement as the market in that when the market moves up/down these stocks also moves up/down by some rate according to their market betas. Also, all the seven stocks had very little unique risk since most of the returns were found to lie on the regression line with very few scattered. Each of the stock had a risk premium of approximately $3 \%$.

\section{References}

[1] Chudhary, K. and Chudhary, S. (2010). Investigating the relationship between stock returns and systematic risk based on CAPM in the Bombay stock exchange. Eurasian Journal of Business and Economics, 3 (6): 127-138.

[2] Elton, E. J. and Gruber, M. J. (1995). Modern Portfolio Theory and Investment Analysis. 5th ed. Wiley, New York.

[3] Fama, E. F. and Macbeth, J. D. (1973). Risk, return and equilibrium: empirical tests. Journal of Politcal Economy, 7: 607-636.

[4] Khaldoun M. A (2011). The Determinants of Systematic Risk in the Jordanian Capital Market. International Journal of Business and Social Sciences, 2 (20): 85-95.

[5] Lintner, J. (1965). The valuation of risk asset and the selection of risk investment in stock portfolio and capital budgets. The Review of Economics and Statistics, 47 (1): 13-37.

[6] Malkiel, B. and Xu, Y. (2005). Idiosyncratic risk and security returns.

[7] McCurby, T. H. and Morgan, I. G. (2011). Intertemporal risk in the foreign currency futures basis. Canadian Journal of Administrative Sciences, 16 (3): 172-184.

[8] Mehrara, M., Fatahati, Z., and Zahiri, N. H. (2014). The relationship between systematic risk and stock returns in Tehran stock exchange using the capital asset pricing model (CAPM). International Letters of Social and Humaniatic Sciences, 21: 26-35.

[9] Omet, G. and Al-Debie, M. (2000). The association between systematic risk and debt to-equity ratio in Amman financial market. Dirasat, the University of Jordan, pages 461-466.

[10] Rodrigures, A. (2009). A modern portfolio theory approach to asset management in the listed South African property market. Master's thesis, Faculty of Engineering, University of Witwatersrand, Johannesburg. Unpublished MSc dissertation, Faculty of Engineering, University of Witwatersrand, Johannesburg.

[11] Sharpe, W. F. (1964). Capital asset prices: a theory of market equilibrium under conditions of risk. Journal of Finance, 19 (3): 425-442.

[12] Sharpe, W. F. and Cooper, G. M. (1972). Risk return classes of New York stock exchange common stocks, 1931-1967. Financial Analysts Journal, 28 (2): 46-81. 